\title{
A SOCIEDADE E SUA RELAÇÃO COM A CIÊNCIA
}

Por volta do século $V$ a.C. a escola de Mileto, entendendo a enorme vantagem da combinação de observação e análise, estabeleceu um modelo em que os discípulos podiam construir, a partir das ideias dos mestres, sem receio de descartar ou criticar o que podia ser melhorado. Nesta escola, Demócrito formulou o conceito do átomo, "a partícula indivisível que constitui a matéria" e postulou que o Universo era composto por espaço ilimitado, populado por uma quantidade inumerável de átomos em movimento [I]. Em tempos semelhantes, a sociedade oriental, tanto no oriente médio como na China e Japão, oferecia liberdade de pensamento e criação, e progressos significativos na medicina, matemática e química, entre outras ciências, foram atingidos. Entretanto, até o final da idade média de nossa era, a sociedade ocidental impôs limites dogmáticos que se estenderam à ciência. Estes limites foram ao ponto de levar a morte os que ousaram divergir, destruir imensas quantidades de livros e escritos e, até, promover guerras "santas". Há vários marcos relevantes do ressurgimento ocidental, mas talvez Francis Bacon, com o método científico, Newton na física e depois Lavoisier com a química e Dalton com os átomos tenham reestabelecido a ciência como a entendemos, em tempos mais tolerantes. Por outro lado, vemos hoje, em uma cronologia similar a das guerras santas do ocidente, destruição de conhecimento e intransigência comparável a "nossa" idade média em partes do mundo - talvez somente contidos pela assimetria de forças reinante no mundo atual. Além destas pressões dramáticas, outras pressões persistem e interferem com a ciência, dependendo de onde ela é feita e por quem é feita. Em algumas áreas da metalurgia, por exemplo, observa-se, em parte do mundo, uma "reinvenção" de conceitos estabelecidos há décadas. Não é claro se o motivo é o orgulho nacional, evitando citar trabalhos anteriores de povos vizinhos que nos séculos recentes avançaram mais rapidamente, ou, simplesmente, a falta da pesquisa bibliográfica consistente e cuidadosa, permitindo que se avance, realmente, ao invés de se "redescobrir a roda". De qualquer forma, há uma influência da sociedade sobre como a pesquisa tecnológica e científica é realizada. Outro exemplo interessante é apontado recentemente na revista Science: A teoria DFT (Density Functional Theory) vem permitindo cálculos fundamentais de energias e estabilidades de compostos, essenciais, por exemplo, para o progresso do método CALPHAD e outros trabalhos que dependem do conhecimento ou previsão da estabilidade de compostos. Entretanto, Medvedev e colaboradores [2] mostraram que, enquanto a precisão das energias calculadas vem aumentando sistematicamente, como desejado, a precisão das densidades eletrônicas, importantes em alguns cálculos, atingiu um máximo por volta do ano 2000 e vem piorando desde então! Pode-se imaginar que a pressão por mais produção científica, mais publicações e mais "invenções" de novos funcionais, de nossa sociedade, tenham uma parcela significativa de culpa no fato?

Por fim, diásporas têm tido enorme papel no desenvolvimento científico e econômico do mundo moderno [3]. O medo e a intolerância vêm limitando o movimento de pessoas em nosso pequeno mundo globalizado. Que impacto devemos esperar na ciência, nos próximos anos?

\section{Boas-vindas}

A equipe Editorial da Revista TMM aproveita a oportunidade para dar as boas-vindas à nova editora executiva da área de Materiais, Prof. ${ }^{a}$ Lidiane Cristina Costa, da UFSCar, desejando-lhe sucesso na nova tarefa e agradecendo antecipadamente à dedicação voluntária.

\section{REFERÊNCIAS}

I Rovelli C. Reality is not what it seems. New York: Riverhead Books-Penguim; 2017.

2 Medvedev MG, Bushmarinov IS, Sun J, Perdew JP, Lyssenko KA. Density functional theory is straying from the path toward the exact functional. Science. 2017;355(6320):49-52.

3 The magic of diásporas. The Economist 2011 Nov 19. 